\title{
The Impact of Body Diversity of Female Media Characters on Preadolescent Self-Esteem: An Assessment of Children's Television Content
}

\author{
Jasmine Kwak* \\ Department of Social \& Consumer Psychology, New York University, USA
}

Submission: March 31, 2021; Published: April 05, 2021

*Corresponding author: Jasmine Kwak, Department of Social \& Consumer Psychology, New York University, USA

\begin{abstract}
There are more forms of media bombarding children than ever before in history, yet not enough of the media has focused on a preadolescent audience. Furthermore, of the content targeting preadolescents, we do not know if it is well-informed through research on preadolescent television-viewing habits. This manuscript reviews recent research on the female characters portrayed in current children's television programs and examines the glorification of female thinness that is most frequently perpetuated in non-Hispanic white media. Results from four studies showed greater body dissatisfaction and lower self-esteem among preadolescents who engaged in peer discussions on body image that glorified the thin ideal. Based on these studies, there is evidence that body diversity by showcasing multiculturalism onscreen can combat the Western thin ideal and increase self-esteem, not only by encouraging and celebrating differences in body types and appearance, but also by shifting the focus of peer conversations away from topics on thinness.
\end{abstract}

Keywords: Pre-adolescence; Children's media; Diversity; Body image; Learning; Peer influence

\section{Body Diversity in Preadolescent Media}

An area of media research that has not yet received adequate attention is pre-adolescent television content. According to Dr. Laurence Steinberg [1], professor of psychology at Temple University, psychological journals tend to focus solely on analyzing adolescents in the context of family and peers, and the hormonal changes they undergo as they emerge adulthood, rather than as independents (p. 84). This inattention for this age group is also portrayed by how television channels dedicated to children are geared more specifically towards younger audiences around the age of preschool and early elementary [2]. Given that there is not yet a consensus on the relationship between youth and the media in psychological research, it is safe to assume that pre-adolescents are within the youth category and are therefore also not given enough recognition. In the Landscape of Children's Television in the US \& Canada, a journal report prepared for The Center for Scholars \& Storytellers, media researchers Dr. Dafna Lemish and Dr. Colleen Russo Johnson (2019) confirm that preadolescents are neglected in media research and describe how "tweens often get left out when it comes to programs specifically created for them" (p. 7). The absence of sufficient formative research and programs for preadolescents and children emerging this age range creates a risk of premature exposure to content inappropriate for their comprehension level as children may turn to watching teenage or adult programming inappropriate for their age [2].

Premature exposure to inappropriate television content could ultimately pose as an obstacle to learning [3]. The following studies analyze the effects of current television programs on young audiences, specifically among young girls ranging from 10 to 12 years old. This age range is also defined by Jean Piaget, one of the first child development psychologists, as the developmental stage in which a child would undergo a cognitive transition from the concrete operational stage of mental operation development to the formal operational stage of abstract thought. According to Piaget, until the age of eleven, a child will not yet be able to comprehend abstract and deductive reasoning and will still be establishing mental operations such as reversibility, conservation, and [4]. This theory of cognitive development therefore indicates that children ages 10 to 12 undergo a developmentally crucial transition yet rely on a scarcity of appropriate media programming that may or may not match their cognitive development due to 
lack of research. Thus, more formative research is necessary in the field of psychology to accommodate this youth population. The following journal articles question the portrayals of body image and diversity in children's television programs and the effects of television-viewing among preadolescent youth.

\section{Television as a Teaching Tool}

The Canadian Paediatric Society (2003), a national association of over 3,000 pediatricians focused on care for children, published a position statement in 2003: "Impact of media use on children and youth", with the goal of evaluating the role that technological devices play in the educational environment of young audiences. The association found that "a substantial number of children begin watching television at an earlier age and in greater amounts than what experts recommend" (p. 301). While the CPS does not explicitly argue whether early exposure generates positive or negative effects on learning, Samantha Goodrich [5] posits in a content analysis on formal features in digital media, that early exposure produces negative effects; referring to the American Academy of Pediatrics' research that concludes that early exposure to screens and adult programs can disrupt brain development, parent-child interaction, and playtime (p. 9). On the contrary, Heather Kirkorian [6], an associate professor in early childhood development, argues in her research article, "Media and Young Children's Learning", that early exposure to televised ageappropriate, educational programs are associated with cognitive and academic enhancement (p. 39).

Between these two viewpoints, the CPS appears to be in accordance with Kirkorian's [6] views that television can be a powerful and beneficial teaching tool when combined with healthy television habits and appropriate content. The CPS (2003) deems that moderation of television exposure is essential, noting that "evidence suggests that television's influence on children and adolescents is related to how much time they spend watching television... [because] watching television takes time away from reading and schoolwork" (p. 301-302). Therefore, the most viable recommendation put forth by the CPS is to implement more "parental involvement in determining desirable programming... to monitor and control their children's viewing habits" (303). Kirkorian [6] supports this recommendation as well, encouraging parents to accommodate a more interactive relationship between children and the media by co-viewing programs to extend children's learning beyond the screen and into "real" life (p. 45). In addition, both the CPS and Kirkorian acknowledge the negative impact of inappropriate, violent television content, addressing how the rise of broadcasted violence in recent years and "early exposure to violent and non-educational entertainment programming was positively associated with later symptoms of attention deficit but exposure to educational television was not related to attentional problems", respectively [6,7].
Thus, the report published by CPS portrays how television has a great influence over preadolescent learning experiences and may generate positive effects depending on the time and amount of exposure and whether that exposure includes educational content. One fact is for certain - more children are watching television programs at an earlier age than ever before. Therefore, providing more age-appropriate and educational material in television programming is essential in response to the increase in young television-viewers; this reinforced the importance of a television series media product geared towards this specific audience and the need to understand the benefits of televised educational content and consider the value in adding more coviewing aspects to make television more conducive to learning.

\section{Effects of Televised Content on Body Image}

Few journal articles in recent years have highlighted the importance of the portrayal of women's bodies in the media: "Sociocultural Influences and Body Image in 9- to 12-Year Old Girls: The Roles of Appearance Schemas" conducted by Levina Clark \& Marika Tiggemann [8], and "Concurrent and Prospective Analyses of Peer, Television and Social Media Influences on Body Dissatisfaction, Eating Disorder Symptoms and Life Satisfaction in Adolescent Girls" conducted by Christopher Ferguson, Monica Munoz, Adolfo Garza \& Mariza Galindo [9]. These studies suggest that while television can be a major teaching tool with enormous influence, peer conversations had a greater impact on self-esteem than did media exposure.

Clark \& Tiggemann [8] focused on answering the question of whether media exposure has a negative influence on body image among pre-adolescents through questionnaires completed by girls ranging from Grades 4 to 7 (p. 76). Given that the median age of the 265 participants was 10.71 years, the sample size of Clark \& Tiggemann's [8] research study informs the need for a preadolescent-oriented television series because their research studies the social effects on an overlooked audience age group (young girls from 10 to 12 years old; i.e. the transition from concrete operational to formal operational stages) to explain how this age range is susceptible to images shown on television (p. 76). This article relates to the necessity for diversity, representation, and inclusion in children's media that a television series conscious of the preadolescent age group aims to resolve - in particular, the necessity for more realistic body portrayals to combat what Clark \& Tiggeman [8] refer to as "the thin ideal" (p. 77). Clark and Tiggemann (2007) note that culture and society play a major role in the construction of body idealization and that young girls are more likely than boys to receive messages from society about their weight and appearance: "the number of preadolescent girls who desire a thinner body size... range between $28 \%$ to $55 \%$... girls between the ages 8 and 11 compared themselves to fashion models and other media images and felt bad about the comparison" ( $p$. 76-77). Likewise, Ferguson et al. [9] study also argues that "media influences on body dissatisfaction may extend to eating disorder 
symptoms, possibly explaining increases in eating disorders such as bulimia nervosa across the twentieth century in Western nations" (p. 1). This argument on the link between the media and eating problems is supported by Lemish \& Johnson [2], who state that "Children are highly influenced by what they see on-screen... the cultural glorification of female thinness and sexualization is correlated with the prevalence of eating disorders and low selfesteem. Showing realistic body types can help boost self confidence in viewers" (p. 17). This article thereby informs the need for more research on preadolescent media consumption and an increase in age-conscious television series as it suggests that young girls are the most vulnerable demographic to body appearance, which affects their self-confidence and increases the risk of developing eating disorders.

The most interesting aspect of Clark \& Tiggeman's [8] study was that "in 9- to 12-year-old girls, exposure to appearance media did not predict body dissatisfaction directly but was predictive of conversations about appearance, which in turn predicted body dissatisfaction" (p. 77). Ferguson et al. (2013) also support this notion in their article, referring to the Catalyst Model which suggests that "peer influences are likely to have a greater influence on body dissatisfaction than media images" (p. 2). In addition, Ferguson et al. [9] results also similarly suggest that "only peer competition, not television or social media use, predicted negative outcomes" (p. 5). Hence, although excessive exposure to media ideals of thinness and attractiveness will increase the likelihood of body dissatisfaction (from failure to meet unattainable ideals), ultimately both Clark \& Tiggeman [8] and Ferguson et al. [9] conclude that peer conversations were more impactful on selfesteem. These results stemming from the lack of diversity in body portrayals in the media should inform content developers of new considerations to implement in television programs.

The background research from Ferguson et al. [9] study sheds light on how body diversity can affect well-being regarding self-esteem of appearance among children. Ferguson et al. [9] describe the major influence of culture on eating behaviors: "eating related pathology is often conceptualized as culturally bound... body dissatisfaction was lower in Hispanic females compared to non-Hispanic whites and suggested that culture, particularly minimization of thin ideals, can be protective for body dissatisfaction issues" (p. 2). Therefore, Ferguson et al. [9] study exemplifies how Western nations such as the United States have embedded into their media, a pervasive glorification of female thinness, which is not necessarily shared in other cultures. Psychologist Lev Vygotsky would agree that cultural appreciation will engender higher cognitive development among children based on his cultural historical theory, which postulates that the unity of mind and culture strengthens children's learning within a social environment as learned cultural beliefs and attitudes affect children's learning [10]. The significance of cultural upbringing is also supported in Steinberg's [1] literature that says, "Research suggests that maintaining ties to both cultures, or biculturalism, is associated with better psychological adjustment" (p. 92). Thus, Steinberg and Vygotsky's research suggests that well-being can be enhanced in the media by acknowledging biculturalism and maintaining positive in-group identities. With the literature from Vygotsky and Steinberg reinforcing Ferguson's emphasis on the importance of culture in children's media, this article, therefore, informs the dire need for appreciation for body differences through diverse and realistically depicted television characters and program curricula centered on topics that generate intellectual peer discussions on topics unrelated to appearance.

\section{Absence of Diversity in Children's Television}

Children already have an affinity for their group identity, exemplified by their preference for socially meaningful characters [3]. However, Toni Schmader and Katharina Block [11] highlight the detrimental stereotypes of ethnic minorities depicted on television to the youth in their research paper: "Social Identity Threat in Response to Stereotypic Film Portrayals: Effects on SelfConscious Emotion and Implicit Ingroup Attitudes". According to Schmader and Block (2015), "Disadvantaged ethnic groups are often portrayed stereotypically in film... Such one-dimensional depictions of groups play a role in the transmission of cultural stereotypes by inaccurately representing behaviors, preferences, and traits within a group" (p. 54-55). This argument that ethnic groups are stereotyped on-screen is supported by Carlos E Cortes [12] in the Children Are Watching: How the Media Teach About Diversity, where he describes how media makers tend to base their products by creating assumptions about the audience; media makers stick to and repeat themes that sell well, thereby overusing specific character traits and creating stereotypes (p. 39). Cortes (2000) notes that "Most of the big media subscribe to certain prejudices" (p. 43). The lack of diversity in children's television, specifically, is noted in Lemish and Johnson's (2019) data on character diversity: "The majority of human characters on children's TV are Caucasian" (p. 14). Lemish \& Johnson [2] state that this poses a risk to children's TV because "without room to explore various facets of both females and people of color, writers are more likely to turn to inaccurate stereotypes" (p. 14). Therefore, Schmader \& Block's [11] argument that minorities are presented largely in stereotypical fashion is in the limelight in studying children's media and proves how there must be more diversity to reduce the perpetuation of these stereotypes.

Schmader \& Block's [11] article also demonstrates how stereotyping is detrimental to children's self-esteem by causing a social identity threat, giving an example of a study on Native American children that concluded: "even brief exposure to stereotypic Native American sports mascots can temporarily lower self-esteem among Native American students" and "the absence of Native Americans in the media can limit the aspirations of Native American children" (p. 55). This shows how stereotypes are not only vastly misrepresenting minority groups in the American media, but also how it particularly affects the self-esteem of young 
children and hinders them from achieving healthy self-esteem and positive aspirations. This idea is supported in Jennifer Kotler, Tanya Haider, and Michael H Levine's [13] study, "Identity Matters: Parents' and Educators' Perceptions of Children's Social Identity and Development". In this study, the evidence that Kotler et al. [13] collected reveals that "children learn best from positive role models. Many scholars have indicated that a paucity of role models exist in mainstream media for certain marginalized groups" ( $p$. 35). This proves Schmader and Block's argument on the negative effects of television stereotypes on young audiences who identify as minority groups, as Kotler et al. [13] agree that children need a strong appreciation of group identity to develop healthy social relationships [13].

Although Schmader \& Block's [11] study focuses on Mexican Americans specifically, the concept of social identity threat emerging from stereotypes of minorities shown on television can be attributed to other minority groups. Thus, from this literature stems new considerations in developing a television series, particularly to create the ethnically diverse characters in TV series in a way that makes them more aspirational. Schmader \& Block [11] note that "people are motivated to have a positive attitude toward their social groups... [and] socially disadvantaged groups members sometimes show more positive implicit attitudes toward higher status groups" (p. 56). Given that people are naturally motivated to view their social identity groups positively yet feel discouraged in their aspirations (as did the Native American students), this implies that American television so far has done a poor job in attributing minority groups to high-status groups and thereby lowers children's self-esteem. Therefore, to combat this trend of television content, media makers need to focus on giving each of the main characters and their families admirable traits and careers so that children will not be hindered from positively associating with their social identity, to foster healthy selfesteem and aspirational goals. Another factor that this literature emphasizes is the importance of focusing on the realism and comedic aspect of the characters. Schmader and Block's [11] study concluded that feelings of shame and self-consciousness were exacerbated among Mexican Americans after watching unrealistic and negatively comedic portrayals of their ethnicity with European Americans (p. 68). This shows how watching highly negative comedic and unrealistic portrayals elicit a higher negative implicit association, which reinforces the benefits of eliminating reliance on comedy to entertain audiences in children's television [14].

\section{Conclusion}

Overall, these four articles helped inform the nature of children's television today and explain how, if used appropriately, television can be used as a teaching tool, shedding light on the negative effects of ideal body portrayals seen on television on conversations among its preadolescent audience, and addressing the absence of diverse TV characters in children's media. These articles connect to important topics of learning from the media and the significance of diversity, representation, and inclusion as shown by the portrayal of body ideals and ethnicities in television content, which media makers can consider in new developments. Ultimately, more research is needed on the preadolescent population as current research reinforces the value of body diversity on well-being. We know through past literature that cultural integration brings about more positive attitudes towards body images through minimization of thin ideals tied heavily to media content created by and for non-Hispanic whites and thereby ensure a healthy psychological development for preadolescent audiences.

\section{References}

1. Steinberg L, Morris AS (2001) Adolescent Development. Annual Review of Psychology 52(1): 83-110.

2. Lemish D, Johnson CR (2019) The Landscape of Children's Television in the US \& Canada. The Center for Scholars \& Storytellers, pp. 1-20.

3. Lauricella AR, Gola AA, Calvert SL (2011) Toddlers' Learning from Socially Meaningful Video Characters. Media Psychology 14(2): 216232.

4. Singer DG, Revenson TA (1979) A Piaget primer: How a child thinks. Internat Univ Pr, New York, USA.

5. Goodrich S (2008) The Formal Features of Digital Media for Infants and Toddlers: A Content Analysis (Master's thesis, Georgetown University, 2008), The Children's Digital Media Center, Washington DC, USA, pp. 1-33.

6. Kirkorian HL, Wartella EA, Anderson DR (2008) Media and Young Children's Learning. Future Child 18(1): 39-61.

7. (2003) Impact of media use on children and youth. Paediatr Child Health 8(5): 301-306.

8. Clark L, Tiggemann M (2007) Sociocultural Influences and Body Image in 9 to 12-Year-Old Girls: The Role of Appearance Schemas. J Clin Child Adolesc Psychol 36 (1): 76-86.

9. Ferguson CJ, Muñoz ME, Garza A, Galindo M (2013) Concurrent and Prospective Analyses of Peer, Television and Social Media Influences on Body Dissatisfaction, Eating Disorder Symptoms and Life Satisfaction in Adolescent Girls. J Youth Adolesc 43(1): 1-14.

10. Diaz-Wionczek M (2020) Socio-Emotional Development. Lecture presented in New York University, New York, USA.

11. Schmader T, Block K, Lickel B (2015) Social Identity Threat in Response to Stereotypic Film Portrayals: Effects on Self-Conscious Emotion and Implicit Ingroup Attitudes. Journal of Social Issues 71(1): 54-72.

12. Cortés CE (2000) The children are watching: How the media teach about diversity. Teachers College Press, New York, USA.

13. Kotler J, Haider T, Levine MH (2019) Identity matters: Parents' and educators' perceptions of children's social identity development. Sesame Workshop, New York, USA, pp. 1-40.

14. Botta RA (1999) Television Images and Adolescent Girls' Body Image Disturbance. Journal of Communication 49(2): 22-41. 
(C) This work is licensed under Creative (c) BY DOI: 10.19080/JGWH.2021.21.556062

\section{Your next submission with Juniper Publishers} will reach you the below assets

- Quality Editorial service

- Swift Peer Review

- Reprints availability

- E-prints Service

- Manuscript Podcast for convenient understanding

- Global attainment for your research

- Manuscript accessibility in different formats

( Pdf, E-pub, Full Tsext, Audio)

- Unceasing customer service

Track the below URL for one-step submission https://juniperpublishers.com/online-submission.php 